\title{
Microbiological study of lactic acid bacteria in kefir grains by culture-dependent and culture-independent methods
}

\author{
Hsi-Chia Chen ${ }^{\mathrm{a}}$, Sheng-Yao Wang ${ }^{\mathrm{a}, \mathrm{b}}$, Ming-Ju Chen ${ }^{\mathrm{a}, \mathrm{c}, *}$ \\ ${ }^{a}$ Department of Animal Science and Technology, National Taiwan University, Taipei 106, Taiwan \\ ${ }^{\mathrm{b}}$ Experimental Farm, National Taiwan University, Taipei 106, Taiwan \\ ${ }^{\mathrm{c}}$ Research Center of Food and Biomolecules, National Taiwan University, Taipei 106, Taiwan
}

Received 20 August 2007; received in revised form 9 January 2008; accepted 13 January 2008

Available online 29 January 2008

\begin{abstract}
Lactic acid bacteria (LAB) in different original kefir grains were first assessed using polymerase chain reaction-denaturing gradient gel electrophoresis (PCR-DGGE) by a culture-dependent way, and were further confirmed by DNA sequencing techniques. Results indicated that a combined method of cultivation with PCR-DGGE and subsequent DNA sequencing could successfully identify four LAB strains from three kefir grains from Taiwan (named Hsinchu, Mongolia and Ilan). Lactobacillus kefiri accounted, in the three kefir grains, for at least half of the isolated colonies while Lb. kefiranofaciens was the second most frequently isolated species. Leuconostoc mesenteroides was less frequently found but still in the three kefir grains conversely to Lactococcus lactis which based on culturedependent isolation was only found in two of the kefir grains. It was interesting to find that all three kefir grains contain similar LAB species. Furthermore, the DGGE as a culture-independent method was also applied to detect the LAB strains. Results indicated that Lb. kefiranofaciens was found in all three kefir grains, whereas Lb. kefiri was only observed in Hsinchu kefir grain and Lc. lactis was found in both Mongolia and Ilan samples. Two additional strains, Pseudomonas spp. and E. coli, were also detected in kefir grains.

(C) 2008 Elsevier Ltd. All rights reserved.
\end{abstract}

Keywords: Lactic acid bacteria; DGGE; Kefir grains; Culture-independent method

\section{Introduction}

Kefir is an acidic and mildly alcoholic fermented dairy product that is believed to have functional properties (Farnworth, 1999, 2006; Farnworth and Mainville, 2003). In Soviet countries, kefir has, anecdotally, been recommended for consumption by healthy people in order to lower the risk of chronic diseases, and has also been provided to certain patients for the clinical treatment of a number of gastrointestinal and metabolic diseases, hypertension, ischemic heart disease (IHD) and allergy (St-Onge et al., 2002; Farnworth and Mainville, 2003). Kefir cultures are also reported to possess the ability to assimilate

\footnotetext{
*Corresponding author at: Department of Animal Science and Technology, National Taiwan University, No. 50, Lane 155, Section 3, Keelung Road, Taipei 106, Taiwan. Tel.: + 886233664169 ; fax: +886227324070 .

E-mail address: cmj@ntu.edu.tw (M.-J. Chen).
}

cholesterol in milk (Vujičič et al., 1992). Kefir differs from other fermented dairy products in that it is the product of fermentation of milk in the presence of a mixed group of microorganisms confined to a matrix of discrete 'kefir grains', which can be recovered for subsequent fermentation (Marshall and Cole, 1985). The microorganisms contained within the kefir grains typically produce lactic acid and antibiotics, such products inhibit the proliferation of both spoilage and pathogenic microorganisms in kefir milk (Farnworth, 2006). However, a stable and constant starter culture, which is necessary for manufacturing a quality kefir beverage, is difficult to sustain due to complex microbiological composition in kefir grains. Detecting and identifying the bacterial compositions of kefir grains and kefir products with rapid method is often important for quality control of this product. On the other hand, the complete description of kefir microflora gives a clue to specify the several bioactive materials produced and in particular those involved in grain-forming mechanism. 
Various lactic acid bacteria (LAB) present in kefir grains or kefir products were isolated and identified by physiological and biochemical tests, including Lactobacillus acidophilus (Angulo et al., 1993), Lb. brevis (Simova et al., 2002), Lb. paracasei subsp. paracasei (Simova et al., 2002), Lb. delbrueckii subsp. (Simova et al., 2002; Witthuhn et al., 2004), Lb. helveticus (Angulo et al., 1993; Lin et al., 1999; Simova et al., 2002), Lb. kefiri (Angulo et al., 1993; Takizawa et al., 1998; Garrote et al., 2001), Lb. kefiranofaciens (Takizawa et al., 1998), Lb. plantarum (Garrote et al., 2001), Leuconostoc mesenteroides subsp. (Lin et al., 1999; Garrote et al., 2001; Witthuhn et al., 2004), Lactococcus lactis subsp. (Garrote et al., 2001; Simova et al., 2002; Witthuhn et al., 2004), Streptococcus thermophilus (Simova et al., 2002). These studies showed the diversity of LAB present in several kefir grain starters. With the rapid development of molecular technologies, various differentiating methods based on genomic traits were applied to microbial classification and displayed diverse applicability. In current bacterial determination procedures, phenotypic features are inappropriate to address the taxonomic nomenclature on the basis of polyphasic classification principles. Random amplified polymorphic DNA (RAPD) and restriction fragment length polymorphism (RFLP) were performed to characterize and type the LAB isolated from kefir grains (Delfederico et al., 2006; Mainville et al., 2006). These studies were both based on the culture-dependent steps and limited to identifying the isolated strains able to grow on the considered nutrient media. Additional weaknesses of these methods include poor reproducibility, ambiguity of experimental results, extensive labor and time-consuming procedures.

Polymerase chain reaction-denaturing gradient gel electrophoresis (PCR-DGGE) is based on amplification of ribosomal RNA and electrophoresis of the PCR product in a polyacrylamide gel containing an increasing gradient of denaturants. Recently, DGGE analysis is recognized as one of the most suitable and widely applied techniques to study complex microbial communities originating from food samples or other environments (Zoetendal et al., 1998; Cocolin et al., 2001; van Beek and Priest, 2002; Ercolini et al., 2003; Temmerman et al., 2004; Lee et al., 2005). Although, many studies clearly demonstrate the broad applicability of this method, the DGGE discriminating capabilities aimed to target bacteria are determined by the choice of the PCR primers. The use of appropriate consensus primers is a critical point to influence the resolution of DGGE analysis in mixed microbial systems, especially in LAB differentiation. Ercolini (2004) reviewed numerous PCR primers used for DGGE analysis to profile the microbial communities in several food systems without pre-cultivation steps. Obviously, the V3 region of $16 \mathrm{~S}$ rDNA is the most popular objective domain to start studying an unknown and complex bacterial community.

Due to the known limitations of phenotypic methods, the aim of this study was to take advantage of PCR-DGGE to identify the LAB rapidly and study their distribution by both culture-dependent and culture-independent methods in three different kefir grains. Identification of the several microorganisms existing in a kefir grains starter is a prerequisite for any in depth study of the mechanism of kefir grain formation or its functional properties toward human health.

\section{Materials and methods}

\subsection{Reference strains and growth conditions}

The reference strains used in this study, except Lc. lactis IO-1, were obtained from the Bioresource Collection and Research Center (Food Industry Research and Development Institute, Hsinchu, Taiwan). Lc. lactis IO-1 was purchased from Japan Collection of Microorganisms (Riken, BioResource Center, Saitama, Japan). The BCRC number and growth conditions of reference strains are listed in Table 1. Except Lc. lactis IO-1, all LAB were cultured with Lactobacilli MRS broth (Difco Laboratories, Detroit, MI, USA) incubated under anaerobic conditions at optimal growth temperature, individually. Lc. lactis IO-1 was cultured with thioglycolate (TGC) medium (Difco) at $37^{\circ} \mathrm{C}$ for $18 \mathrm{~h}$.

\subsection{Kefir grains}

Three kefir grains, collected from Taiwan (named Hsinchu, Ilan and Mongolia), were evaluated in this study. In the laboratory, $10 \%(\mathrm{w} / \mathrm{w})$ of each grain was propagated at $20^{\circ} \mathrm{C}$ for $20 \mathrm{~h}$ with two to three weekly transfers in sterilized milk, and kept at 4 and $-80^{\circ} \mathrm{C}$ for short- and long-term storage, respectively.

\subsection{Lactic acid bacteria isolation and cultivation from kefir grains}

Kefir grains were recovered from the mother culture having reached the fermentative end-point. Ten grams of each kefir grains were suspended in $90 \mathrm{~g}$ of sterile saline buffer $(0.85 \% \mathrm{NaCl})$ and homogenized with a Stomacher (Laboratory Blender Stomacher 400, Seward, UK) for $20 \mathrm{~min}$. Serial dilutions of the suspended samples were used for microbial enumerations and isolation by MRS agar (Acumedia, Lansing, MI, USA) under both aerobic and anaerobic conditions, and by LM17 agar [M17 agar (Difco) with $0.5 \%$ (w/v) lactose (Sigma, St. Louis, MO, USA)] under aerobiosis. In addition, $200 \mathrm{ppm}$ cycloheximide (Sigma) was also added for both MRS and LM17 agars to inhibit the growth of yeasts. The plates were incubated at $30^{\circ} \mathrm{C}$ for 7 days and the resulting colonies were counted before single colony purification.

To determine the distribution of LAB in each kefir grain, at least $10 \%$ of total colonies were selected randomly from each plate with 30-300 colonies and transferred to MRS broth (Difco) for further identification by PCR-DGGE. 
Table 1

Bacterial strains used as reference patterns of PCR-DGGE for this study

\begin{tabular}{|c|c|c|c|}
\hline \multirow[t]{2}{*}{ Species or subspecies } & \multirow[t]{2}{*}{ Strain $^{\mathrm{a}}$} & \multicolumn{2}{|c|}{ Growth conditions } \\
\hline & & Broth & Temperature $\left({ }^{\circ} \mathrm{C}\right)$ \\
\hline Lactobacillus acidophilus & BCRC 14079 & MRS & 37 \\
\hline Lactobacillus brevis & BCRC $10361=$ ATCC 8287 & MRS & 30 \\
\hline Lactobacillus casei & $\mathrm{BCRC} 10697^{\mathrm{T}}=\mathrm{ATCC} 393$ & MRS & 37 \\
\hline Lactobacillus delbrueckii subsp. bulgaricus & BCRC $10696^{\mathrm{T}}=$ ATCC 11842 & MRS & 37 \\
\hline Lactobacillus delbrueckii subsp. delbrueckii & BCRC $12195^{\mathrm{T}}=$ ATCC 9649 & MRS & 37 \\
\hline Lactobacillus delbrueckii subsp. lactis & $\mathrm{BCRC} 12256^{\mathrm{T}}=\mathrm{ATCC} 12315$ & MRS & 37 \\
\hline Lactobacillus helveticus & BCRC $12936^{\mathrm{T}}=$ ATCC 15009 & MRS & 37 \\
\hline Lactobacillus kefiranofaciens subsp. kefiranofaciens & BCRC $16059^{\mathrm{T}}=$ ATCC 15742 & MRS, pH 5.5 & 37 \\
\hline Lactobacillus kefiri & BCRC $14011^{\mathrm{T}}=$ ATCC 35411 & MRS & 37 \\
\hline Lactobacillus paracasei subsp. paracasei & BCRC $14023=$ ATCC 27092 & MRS & 37 \\
\hline Lactobacillus plantarum & BCRC $12251=$ ATCC 10241 & MRS & 37 \\
\hline Lactobacillus rhamnosus & BCRC $16000=$ ATCC 53103 & MRS & 37 \\
\hline Lactobacillus sake & $\mathrm{BCRC} 14622^{\mathrm{T}}=\mathrm{ATCC} 15521$ & MRS & 30 \\
\hline Lactococcus lactis subsp. cremoris & BCRC $12586^{\mathrm{T}}=$ ATCC 19257 & MRS & 26 \\
\hline Lactococcus lactis subsp. lactis & BCRC $14117=$ ATCC 11007 & MRS & 30 \\
\hline Lactococcus lactis IO-1 & JCM 7638 & TGC & 37 \\
\hline Leuconostoc mesenteroides subsp. cremoris & BCRC $14047^{\mathrm{T}}=$ ATCC 19254 & MRS & 30 \\
\hline Leuconostoc mesenteroides subsp. dextranicum & BCRC $14052^{\mathrm{T}}=$ ATCC 19255 & MRS & 30 \\
\hline Leuconostoc mesenteroides subsp. mesenteroides & BCRC $12580=$ NCTC 3352 & MRS & 30 \\
\hline Streptococcus thermophilus & BCRC 12268 & MRS & 37 \\
\hline
\end{tabular}

${ }^{a}$ BCRC, Bioresource Collection and Research Center; ATCC, American Type Culture Collection; NCTC, National Collection of Type Cultures; JCM, Japan Collection of Microorganisms. ${ }^{\mathrm{T}}$ Type strain.

\subsection{DNA isolation}

One milliliter of each late-exponential-phase culture was collected by centrifugation at $7500 \times g\left(10 \mathrm{~min}, 4^{\circ} \mathrm{C}\right)$. Kefir grains were washed with sterilized water and $0.5 \mathrm{~g}$ of each sample was put into a plastic tube. The bacterial pellets and kefir grains were subjected to DNA extraction using a blood and tissue genomic DNA extraction system. DNA extraction according to the manufacturer's instructions (Viogene-Biotek Corp., Taipei, Taiwan) included protein lysis and isolation of genomic DNA. The pellets were first lysed by proteinase $\mathrm{K}$. The genomic DNA was then isolated by silica-gel-membrane technology and centrifugation. Finally, genomic DNA was resuspended in sterilized $\mathrm{ddH}_{2} \mathrm{O}$ and stored at $-20^{\circ} \mathrm{C}$.

\subsection{PCR-DGGE analysis}

PCR was performed in a total reaction volume of $50 \mu \mathrm{L}$ containing $0.2 \mu \mathrm{M}$ of each primer, $1.25 \mathrm{U}$ of Taq DNA polymerase (Yeastern Biotech, Taipei, Taiwan), $5 \mu \mathrm{L}$ of

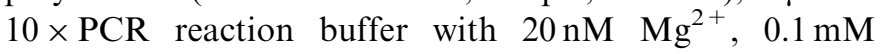
dNTPs mix and $1 \mu \mathrm{L}$ of the template DNA. Amplification was achieved in $0.2 \mathrm{~mL}$ tubes by using a Biometra T3000 thermocycler (Biometra, Göttingen, Germany).

The primer set, 338f (5'-ACT CCT ACG GGA GGC AGC AG-3') and 518r (5'-ATT ACC GCG GCT GCT GG- $3^{\prime}$ ), spanned the $\mathrm{V} 3$ region of the $16 \mathrm{~S}$ rDNA. The $338 \mathrm{f}$ GC primer has a GC clamp (5'-CGC CCG CCG CGC GCG GCG GGC GGG GCG GGG GCA CGA GGG G$3^{\prime}$ ) attached to the $5^{\prime}$ end of primer $338 \mathrm{f}$ (Cocolin et al.,
2001) to identify the closely phylogenetic relationship of 20 LAB. A touchdown PCR was carried out (Ercolini et al., 2001) with $338 \mathrm{f} \mathrm{GC} / 518 \mathrm{r}$ to increase the specificity of the amplification and reduce the formation of spurious byproducts. The PCR products were generated using an initial denaturation step of $5 \mathrm{~min}$ at $94{ }^{\circ} \mathrm{C}$ followed by denaturation at $94{ }^{\circ} \mathrm{C}$ for $30 \mathrm{~s}$. The annealing temperature of $65^{\circ} \mathrm{C}$ for $30 \mathrm{~s}$ was decreased by $1{ }^{\circ} \mathrm{C}$ at each of the successive cycles until the touchdown temperature of $55^{\circ} \mathrm{C}$ was reached and the remaining 20 cycles were accomplished at $55^{\circ} \mathrm{C}$ for $1 \mathrm{~min}$. The elongation step was conducted at $72^{\circ} \mathrm{C}$ for $3 \mathrm{~min}$. A final chain extension at $72{ }^{\circ} \mathrm{C}$ for $10 \mathrm{~min}$ was done. Amplified products were run on a 2\% agarose gel (Nippon Gene, Toyama, Japan), stained with ethidium bromide (Fluka-Riedel-de Haen, Basel, Switzerland) and visualized under UV light.

Parallel DGGE was performed by using a DCode ${ }^{\mathrm{TM}}$ universal mutation detection system (Bio-Rad, Hercules, CA, USA) with gels of $16 \times 16 \times 0.01 \mathrm{~cm}$. Eight percent polyacrylamide gels were prepared and run with $1 \times \mathrm{TAE}$ buffer $(0.04 \mathrm{M}$ Tris-acetate and $0.001 \mathrm{M}$ EDTA) diluted with $50 \times$ TAE buffer (Amersco, Solon, OH, USA). To analyze the PCR amplicons, the denaturing gradient was formed with two $8 \%(\mathrm{w} / \mathrm{v})$ acrylamide (acrylamide/bis, 37.5:1) stock solutions (Amersco). The gels contained a $30-55 \%$ gradient of urea (J.T. Baker, Phillipsburg, NJ, USA) and deionized formamide (J.T. Baker) increasing in the direction of the DNA migration during a run. A $100 \%$ denaturing solution contained $40 \%(\mathrm{v} / \mathrm{v})$ formamide and $7.0 \mathrm{M}$ urea. The electrophoresis was conducted with a constant voltage of $50 \mathrm{~V}$ for $10 \mathrm{~min}$ and $200 \mathrm{~V}$ for $3.5 \mathrm{~h}$ at 
$60{ }^{\circ} \mathrm{C}$. PCR samples $(5 \mu \mathrm{L})$ were put on the gels with $5 \mu \mathrm{L}$ loading dye per lane. Decasted gels were stained with ethidium bromide solution $(5 \mu \mathrm{g} / \mathrm{mL}, 5 \mathrm{~min})$, washed with deionized water for $5 \mathrm{~min}$, and viewed under UV transillumination. The gel images were photographed using the GelDoc-It system (UVP, Upland, CA, USA).

\subsection{DNA sequencing}

The isolated strains were further confirmed by $16 \mathrm{~S}$ rDNA full-length sequencing. A fragment of approximately $1500 \mathrm{bp}$ of the $16 \mathrm{~S}$ rDNA was amplified by forward primer 8f $\left(5^{\prime}\right.$-AGA GTT TGA TCC TGG CTC AG- $\left.3^{\prime}\right)$ and reverse primer 1512r (5'-AAG GAG GTG ATC CAG CCG CA-3') (Coenye et al., 1999). The PCR products were purified by using PCR-M clean up system (Viogene) and then submitted to sequencing according to the method mentioned by Coenye et al. (1999). The sequence identities were determined by BLAST program in the GenBank database (Altschul et al., 1997).

Different DGGE bands, especially the ones that could not be identified by comparing to the reference marker, were excised form the acrylamide gels. The DNA fragments were purified using QIAEX $^{\circledR}$ II gel extraction kit (Qiagen, Chatsworth, CA, USA) and then re-amplified by the primer $338 \mathrm{f}$ (without GC clamp) and 518r. The PCR amplicons were subjected to PCR-M clean up system (Viogene) before sequencing. The sequence identities were determined by BLAST in the GenBank database.

\section{Results and discussion}

\subsection{Differentiation of lab strains by PCR-DGGE analysis}

The results obtained by PCR-DGGE analysis using a $30-55 \%$ DGGE gel on 20 reference strains (Table 1) that either have been identified in kefir grains or are commonly used in fermented milk are shown in Fig. 1. As reported, Lb. sake (lane 5), Lb. delbrueckii subsp. bulgaricus (lane 8), Lb. delbrueckii subsp. delbrueckii (lane 9), Lb. kefiranofaciens subsp. kefiranofaciens (lane 11), Lb. kefiri (lane 16), and Str. thermophilus (lane 17) gave specific electrophoretic patterns that could be easily used for identification purposes. Lb. delbrueckii subsp. lactis (lane 10) presented two DGGE bands due to the amplification of multi-copies of the ribosomal genes that would allow precise species identification by DGGE, as previously described by Cocolin et al. (2001). However, Lb. brevis (lane 1) and Lb. plantarum (lane 2) had similar patterns in the gel that could not be identified. Likewise, same results happened to the following five groups: Leu. mesenteroides subsp. dextranicum (lane 3) and Leu. mesenteroides subsp. mesenteroides (lane 4); Lb. acidophilus (lane 6) and Lb. helveticus (lane 7); Lc. lactis subsp. lactis (lane 12) and Leu. mesenteroides subsp. cremoris (lane 13); Lc. lactis subsp. cremoris (lane 14) and Lc. lactis IO-1 (lane 15); Lb. casei (lane 18), Lb. rhamnosus (lane 19) and Lb. paracasei subsp. paracasei (lane 20).

Interestingly, at subspecies level, DGGE profiles of Lb. delbrueckii subsp. bulgaricus, Lb. delbrueckii subsp.

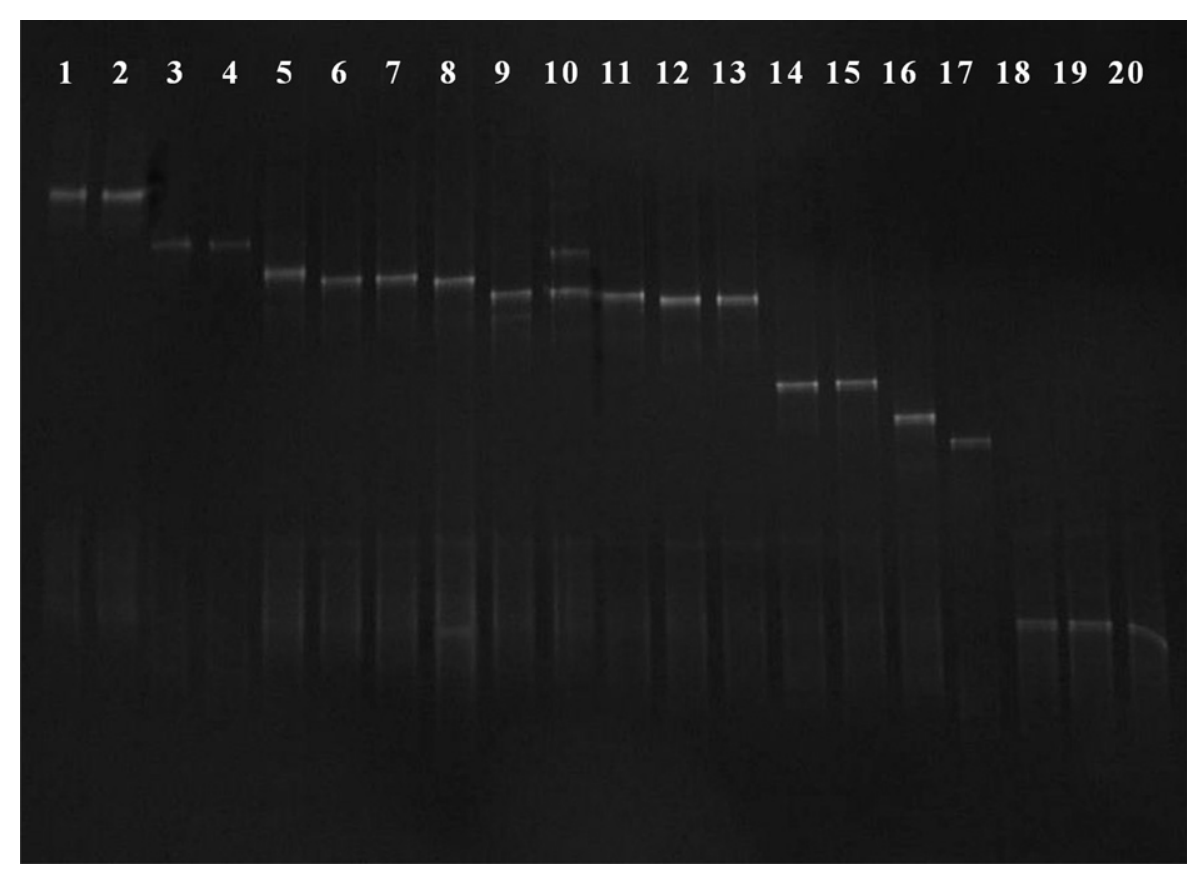

Fig. 1. DGGE profiles of 20 reference LAB strains with denaturing gradient from $30 \%$ to $55 \%$. Lane 1, Lb. brevis; lane 2, Lb. plantarum; lane 3, Leu. mesenteroides subsp. dextranicum; lane 4, Leu. mesenteroides subsp. mesenteroides; lane 5, Lb. sake; lane 6, Lb. acidophilus; lane 7, Lb. helveticus; lane 8, Lb. delbrueckii subsp. bulgaricus; lane 9, Lb. delbrueckii subsp. delbrueckii; lane 10, Lb. delbrueckii subsp. lactis; lane 11, Lb. kefiranofaciens subsp. Kefiranofaciens; lane 12, Lc. lactis subsp. lactis; lane 13, Leu. mesenteroides subsp. cremoris; lane 14, Lc. lactis subsp. cremoris; lane 15, Lc. lactis subsp. IO1; lane 16, Lb. kefiri; lane 17, Str. thermophilus; lane 18, Lb. casei; lane 19, Lb. rhamnosus; lane 20, Lb. paracasei subsp. paracasei. 
delbrueckii and Lb. delbrueckii subsp. lactis could be easily distinguished. On the other hand, among the three Lc. lactis subspecies (lanes 12, 14 and 15 in Fig. 1), only Lc. lactis subsp. lactis appeared to have a unique pattern that could be directly identified by DGGE, but Lc. lactis IO-1 and Lc. lactis subsp. cremoris showed identical patterns. In previous research, Ward et al. (1998) also successfully differentiated both Lc. lactis subsp. lactis and Lc. lactis subsp. cremoris based on 16S RNA sequence, but Ercolini et al. (2001) could not use the V3 region from $16 \mathrm{~S}$ rDNA to identify these two subspecies of $L c$. lactis. A recent study indicated that $L b$. casei, Lb. paracasei and $L b$. rhamnosus belonged to the $L b$. casei group (Felis and Dellaglio, 2007). Our results showed that these three species could not be differentiated by DGGE. Walter et al. (2000) also failed to distinguish $L b$. casei and Lb. rhamnosus using DGGE or BLAST comparisons of V2-V3 sequences. The authors suggested that differentiation of these species might be possible by using primers targeting other regions of the $16 \mathrm{~S}$ rRNA. In fact, only a few differences in base pairs between 16S rRNA sequences among species or subspecies provide a different migration pattern in a DGGE gel that may be used for the differentiation of these sequences but the resolution power is also a function of the $16 \mathrm{~S} \mathrm{rDNA}$ region that is targeted.

The above results indicated that some LAB reference strains were undifferentiated by the migration of their V3 regions of $16 \mathrm{~S}$ rDNA in a DGGE analysis. In those cases, the species or subspecies distinction might be achieved by analyzing other variable genetic domains or integrated with additional distinguishable methods. Temmerman et al. (2004) also reported that if too many different species are present, the DGGE pattern requires further analysis, for instance by sequencing, to be identified.

\subsection{Culture-dependent method}

\subsubsection{LAB isolation conditions}

Traditionally, many plating procedures are only partially selective and exclude parts of the microbial community. In order to find out all kinds of LAB from Taiwanese kefir grains, three different enriched treatments (MRS agar with aerobic cultivation, MRS agar with anaerobic cultivation, LM17 agar with aerobic cultivation) were tested to count and isolate LAB colonies in Hsinchu kefir grains. Results indicated that the selectivity of the media used to isolate LAB was found to be non-specific. Two strains (named HL1 and HL2) grew on all three media (Fig. 2), whereas HL3 and HL4 strains could only be isolated from MRS agar with aerobic cultivation. In the case of kefir grains, the MRS medium was the most suitable for the isolation of LAB. Thus, MRS agar with aerobic cultivation was selected as isolation medium for the subsequent culturedependent studies.

Even if many studies focused on the selection of a suitable selective growth medium for LAB, most media were not fit for the growth of certain strains found in kefir grains (Farnworth and Mainville, 2003). Kojima et al. (1993) compared with the viable cell numbers detected by using eight different agar media in kefir grains and indicated that R-CW agar medium was assessed as a medium suitable for the isolation and cultivation of lactobacilli. Takizawa et al. (1994) isolated homofermentative and heterofermentative lactobacilli from kefir grains by using R-CW agar medium and identified $L b$. kefirgranum and $L b$. parakefir. Witthuhn et al. (2004) tried to isolate the lactobacilli, lactococci, leuconostocs, acetic acid bacteria and propionibacteria by using five different selective media. After further identification using the API 50 CHL system, they found that some bacteria could grow on more than one medium. Witthuhn et al. (2005) emphasized that careful consideration should be given before making conclusions about the microorganisms of a fermentation environment based on media selectivity alone.

\subsubsection{Classification and identification of $L A B$ isolated from kefir grains by $D G G E$}

There were 69, 50 and 55 colonies in Hsinchu, Mongolia and Ilan kefir grains, respectively, isolated and classified by PCR-DGGE. The profiles (Figs. 2a and 3) illustrated that four different LAB strains (named HL1, HL2, HL3 and HL4) were found in Hsinchu kefir grains (Fig. 2a), and another four strains (named ML1, ML2, ML3 and ML4) were observed in Mongolia kefir grains (Figs. 3a and b). While only three strains (named IL1, IL2 and IL3) were discovered in Ilan kefir grains (Fig. 3c).

The results of further LAB identification by DGGE were also shown in Figs. 2a and 3. Compared with band positions of reference strains, both Hsinchu and Mongolia kefir grains contained Lb. kefiranofaciens (HL1, ML1), Lb. kefiri (HL2, ML2), Leu. mesenteroides (HL3, ML3) and Lc. lactis (HL4, ML4). Whereas, Lb. kefiranofaciens (IL1), Lb. kefiri (IL2), Leu. mesenteroides (IL3) were identified in Ilan kefir grains. In order to verify the PCRDGGE results, the full length of $16 \mathrm{~S}$ rDNA were sequenced as further confirmation. After alignment was carried out in BLAST, sequences results showed $99-100 \%$ identity with the sequences, which were retrieved from GenBank accession numbers (Table 2). No differences were observed in species identification based on sequence results with retrieving the species from GenBank comparisons and based on PCR-DGGE.

Identification results indicated that kefir grains from Taiwan contained a diverse spectrum of species and genera of microorganisms including lactobacilli, lactococci and leuconostocs. $L b$. kefiranofaciens and $L b$. kefiri, isolated from three Taiwanese kefir grains, were common LAB strains observed in kefir grains (Angulo et al., 1993; Takizawa et al., 1998; Ninane et al., 2007), that even totally matched with the RFLP results demonstrated by Mainville et al. (2006). Additionally, it is interesting to note that all three kefir grains contain similar LAB strains. Farnworth and Mainville (2003) reviewed the results from different original kefir grains and concluded that the list of 
a
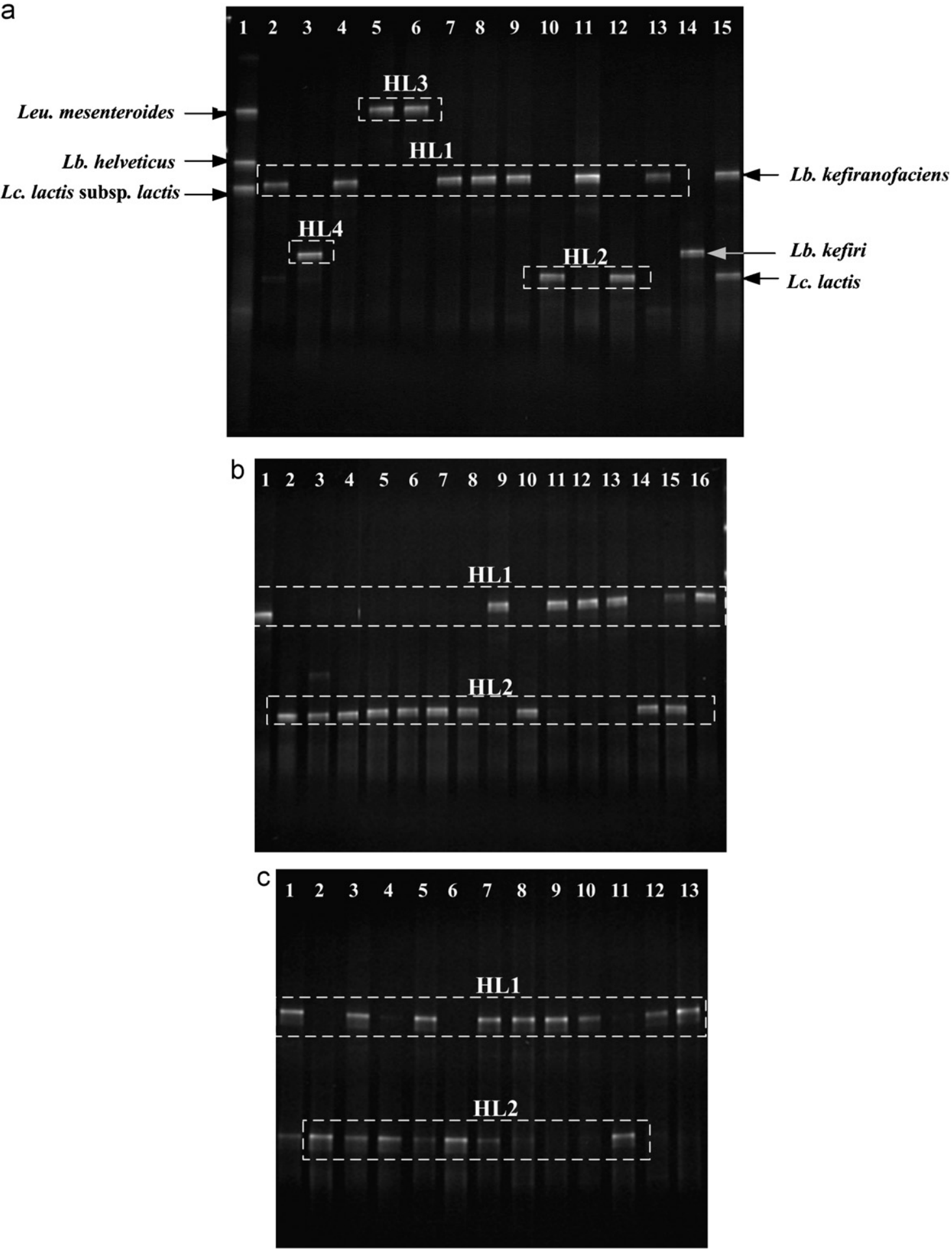

Fig. 2. DGGE profiles of bacterial isolates from Hsinchu kefir under different culture conditions: (a) MRS agar, aerobic cultivation; (b) MRS agar, anaerobic cultivation; and (c) LM17 agar, aerobic cultivation.

microorganisms in kefir grains would not be very extensive, even from different parts of the world.

Many studies have investigated the composition of the microorganisms present in kefir grains and reported that Lactobacillus is the most frequently found microbe. In this research, Lb. kefiri seemed to be the most easily detectable bacteria in all three kefir grains (Table 2). However, this result should be cautiously evaluated. Arihara et al. (1990) applied immunofluorescence microscopy to observe the in situ location of Lb. kefiranofaciens and Lb. kefiri in kefir grains. Under ultraviolet illumination, Lb. kefiranofaciens was detected over the entire section of the kefir grain and increased toward the center, while $L b$. kefiri populated only at a small region on the surface layers. In our study, 

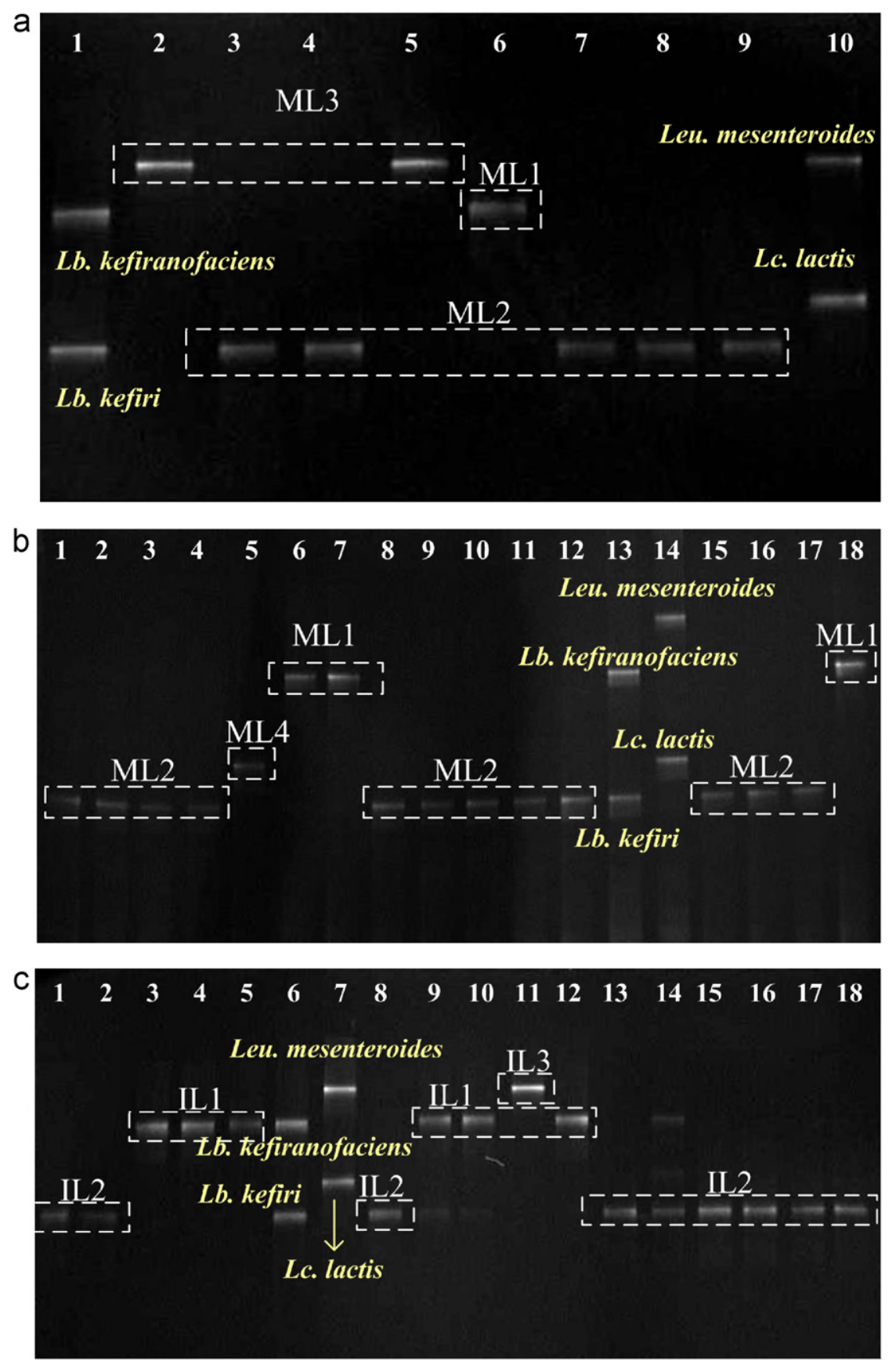

Fig. 3. DGGE classification of LAB strains isolated from ((a) and (b)) Mongolia kefir grains, and (c) Ilan kefir grains. (a) Lanes 2-9, isolated strains; lane 1, Lb. kefiranofaciens and Lb. kefiri; lane10, Leu. mesenteroides subsp. dextranicum and Lc. lactis subsp. cremoris. (b) Lanes 1-12, 15-18, isolated strains; lane 13, Lb. kefiranofaciens and Lb. kefiri; lane 14, Leu. mesenteroides subsp. dextranicum and Lc. lactis subsp. cremoris. (c) Lanes 1-5, 8-18, isolated strains; lane 6, Lb. kefiranofaciens and Lb. kefiri; lane 7, Leu. mesenteroides subsp. dextranicum and Lc. lactis subsp. cremoris.

Lb. kefiri fixed on the grain surface might be easily freed from kefir grains into the saline buffer under the mechanical blending resulting in the increased cell counts of this strain.

\subsection{Identification of LAB in kefir grains by culture- independent method}

Since many plating procedures are only partially selective and exclude part of the microbial community, total DNA of bacterial strains in kefir grains were extracted and directly identified by PCR-DGGE. Results (Fig. 4) indicated that $L b$. kefiranofaciens was found in all three kefir grains, whereas Lb. kefiri was only observed in Hsinchu kefir grain and Lc. lactis was found in both Mongolia and Ilan samples. It was interesting to find that Lc. lactis, which was not detected in the culturedependent method, was found in Ilan samples. The possible explanation might be that this strain, due to its scarcity (Table 2), was not selected from the plates. 
Table 2

Sequences information from the 16S rDNA obtained from the LAB species isolated from three kefir grains

\begin{tabular}{|c|c|c|c|c|}
\hline Classified group & Closest relative & Identity $^{\mathrm{a}}(\%)$ & Accession number & $\begin{array}{l}\text { Distribution (\%) (identified } \\
\text { number/total isolates) }\end{array}$ \\
\hline \multicolumn{5}{|l|}{ Hsinchu } \\
\hline HL2 & Lb. kefiri & 99 & AY579584 & $53(36 / 69)$ \\
\hline HL3 & Leu. mesenteroides & 100 & AY675249 & $3(2 / 69)$ \\
\hline HL4 & Lc. lactis & 100 & DQ523490 & $1(1 / 69)$ \\
\hline ML2 & Lb. kefiri & 100 & AY363303 & $58(29 / 50)$ \\
\hline ML3 & Leu. mesenteroides & 99 & AY675249 & $16(12 / 50)$ \\
\hline ML4 & Lc. lactis & 100 & DQ523490 & $2(1 / 50)$ \\
\hline \multicolumn{5}{|l|}{ Ilan } \\
\hline IL1 & Lb. kefiranofaciens & 100 & AJ575259 & $40(22 / 55)$ \\
\hline
\end{tabular}

${ }^{a}$ Identical nucleotides percentage in the sequence obtained from the agarose band and the sequence obtained found in NCBI.

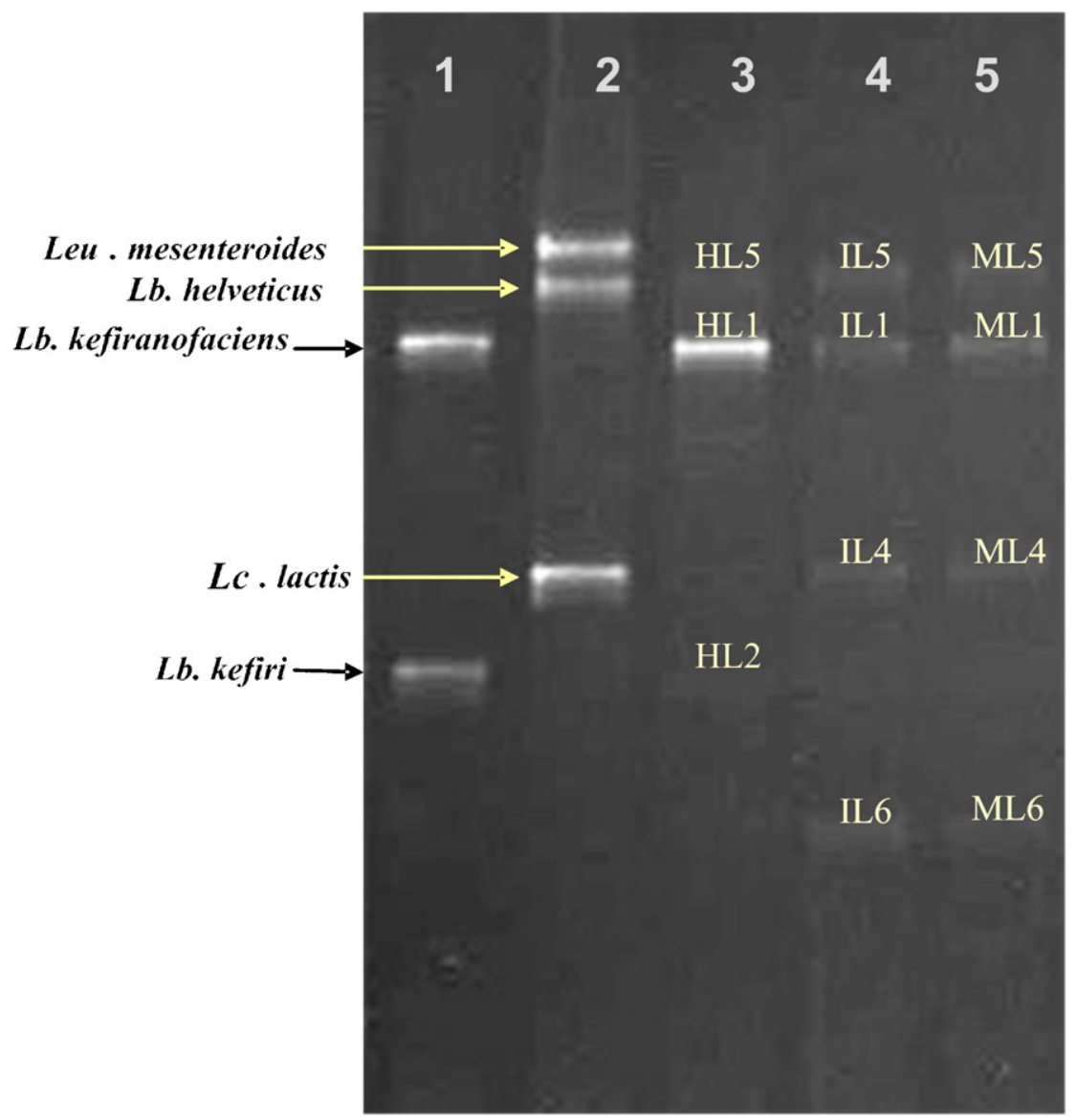

Fig. 4. DGGE analysis of the PCR amplicons derived from three different kefir grains. Lanes 1 and 2, reference ladder; lane 3, kefir grains from Hsinchu; lane 4, kefir grains from Ilan; lane 5, kefir grains from Mongolia.

Additionally, analyzing the kefir milk after fermentation process and storage at $4{ }^{\circ} \mathrm{C}$ for $12 \mathrm{~h}$ using PCR-DGGE (data not shown), Lc. lactis, a common LAB found in kefir and kefir grains (Farnworth and Mainville, 2003; Witthuhn et al., 2005), was also observed in Ilan kefir milk. The changes of bacteria composition releasing into milk from 
kefir grains during the fermentation and ripening in the refrigerator should be another research topic we proceed to investigate.

One additional DGGE band (named HL5) in Hsinchu kefir grain and two additional bands (named ML5 and ML6; IL5 and IL6) in both Mongolia and Ilan kefir grains were found. Further identification by DNA sequencing revealed that they were E. coli fragment (IL6 and ML6) and Pseudomonas spp. (HL5, ML5 and IL5), which were not LAB strains. It is possible that both strains were contaminated microorganisms adopted from environment. Kourkoutas et al. (2006) also discovered Pseudomonas genus in the DGGE fingerprinting when using kefir as a starter in feta-type cheese manufacture.

PCR-DGGE eliminates the necessity for strain isolation, thereby negating the potential biases inherent to microbial enrichment. However, the varieties of the LAB strains identified by PCR-DGGE were less than those identified with the use of initial enrichment stage on nutritive media. Possible explanations might be that the cell numbers of certain LAB species were lower than the detection limit of PCR-DGGE (Theunissen et al., 2005). Fasoli et al. (2003) defined that the sensitivity of DGGE for the detection of $\mathrm{V} 2-\mathrm{V} 3$ region in a complex environment was $10^{7}-10^{8} \mathrm{cfu} / \mathrm{g}$. The limitation for the detection potential is a consequence of high quantities of competitor templates during the amplification reactions (Fasoli et al., 2003). Kefir grains contained large amounts of DNA from other microbial groups that had the potential to interfere with the specific PCR-amplification of LAB DNA and might compromise the reliability and quality of the data obtained by DGGE. Moreover, species with a large population size in the mixture might give greater amounts of template DNA, and therefore had a higher probability of detection (Prakitchaiwattana et al., 2004). Besides, various cell proteins and culture ages may interact with the genomic DNA, thereby affecting primer annealing to the template or affecting the activity of the DNA polymerase (de Barros Lopes et al., 1996; Beh et al., 2006).

\section{Conclusion}

The results obtained in this study show that a combined method of cultivation with PCR-DGGE and subsequent DNA sequencing could successfully identify four LAB species from three kefir grains from Taiwan. It is interesting to notice that all three kefir grains contain similar LAB species. Furthermore, the DGGE was also applied to detect the LAB strains in kefir grains and evaluated its discriminating potential by the results derived from the DGGE by a culture-dependent way. Although several LAB strains, which were previously identified by the culture-dependent method, were not detected, several additional bacteria were indeed revealed by this cultureindependent method.

\section{Acknowledgment}

This research was financially supported by the National Science Council (NSC 95-2313-B-002-058-MY3), Taiwan, ROC.

\section{Reference}

Altschul, S.F., Madden, T.L., Schaffer, A.A., Zhang, J., Zhang, Z., Miller, W., Lipman, D.J., 1997. Gapped BLAST and PSI-BLAST: a new generation of protein database search programs. Nucleic Acids Res. 25, 3389-3402.

Angulo, L., Lopez, E., Lema, C., 1993. Microflora present in kefir grains of the Galician region (North-West of Spain). J. Dairy Res. 60, 263-267.

Arihara, K., Toba, T., Adachi, S., 1990. Immunofluorescence microscopic studies on distribution of Lactobacillus kefiranofaciens and Lactobacillus kefir in kefir grains. Int. J. Food Microbiol. 11, 127-134.

Beh, A.L., Fleet, G.H., Prakitchaiwattana, C., Heard, G.M., 2006. Evaluation of molecular methods for the analysis of yeasts in foods and beverages. Adv. Exp. Med. Biol. 571, 69-106.

Cocolin, L., Manzano, M., Aggio, D., Cantoni, C., Comi, G., 2001. A novel polymerase chain reaction (PCR)-denaturing gradient gel electrophoresis (DGGE) for the identification of Micrococcaceae strains involved in meat fermentation. Its application to naturally fermented Italian sausages. Meat Sci. 57, 59-64.

Coenye, T., Falsen, E., Vancanneyt, M., Hoste, B., Govan, J.R.W., Kersters, K., Vandamme, P., 1999. Classification of Alcaligenes faecalis-like isolates from the environment and human clinical samples as Ralstonia gilardii sp. nov. Int. J. Syst. Bacteriol. 49, 405-413.

de Barros Lopes, M., Soden, A., Henschke, P.A., Langridge, P., 1996. PCR differentiation of commercial yeast strains using intron splice site primers. Appl. Environ. Microbiol. 62, 4514-4520.

Delfederico, L., Hollmann, A., Martínez, M., Iglesias, N.G., de Antoni, G., Semorile, L., 2006. Molecular identification and typing of lactobacilli isolated from kefir grains. J. Dairy Res. 73, 20-27.

Ercolini, D., 2004. PCR-DGGE fingerprinting: novel strategies for detection of microbes in food. J. Microbiol. Methods 56, 297-314.

Ercolini, D., Moschetti, G., Blaiotta, G., Coppola, S., 2001. Behavior of variable V3 region from $16 \mathrm{~S}$ rDNA of lactic acid bacteria in denaturing gradient gel electrophoresis. Curr. Microbiol. 42, 199-202.

Ercolini, D., Hill, P.J., Dodd, C.E.R., 2003. Bacterial community structure and location in Stilton cheese. Appl. Environ. Microbiol. 69, 3540-3548.

Farnworth, E.R., 1999. Kefir: from folklore to regulatory approval. J. Nutra. Funct. Med. Foods 1, 57-68.

Farnworth, E.R., 2006. Kefir - a complex probiotic. Food Sci. Technol. Bull.: Funct. Foods 2, 1-17 〈http://www.foodsciencecentral.com/fsc/ bulletin-ff-free $>$.

Farnworth, E.R., Mainville, I., 2003. Kefir: a fermented milk product. In: Farnworth, E.R. (Ed.), Handbook of Fermented Functional Foods. CRC Press, Boca Raton, FL, pp. 77-112.

Fasoli, S., Marzotto, M., Rizzotti, M., Rossi, L., Dellaglio, F., Torriani, S., 2003. Bacterial composition of commercial probiotic products as evaluated by PCR-DGGE analysis. Int. J. Food Microbiol. 82, 59-70.

Felis, G.E., Dellaglio, F., 2007. Taxonomy of Lactobacilli and Bifidobacteria. Curr. Issues Intest. Microbiol. 8, 44-61.

Garrote, G.L., Abraham, A.G., de Antoni, G.L., 2001. Chemical and microbiological characterization of kefir grains. J. Dairy Res. 68, 639-652.

Kojima, S., Takizawa, S., Tamura, S., Fujinaga, S., Benno, Y., Nakase, T., 1993. Improved medium for the isolation of lactobacilli from kefir grains. Biosci. Biotechnol. Biochem. 57, 119-120.

Kourkoutas, Y., Kandylis, P., Panas, P., Dooley, J.S.G., Nigam, P., Koutinas, A.A., 2006. Evaluation of freeze-dried kefir coculture as starter in feta-type cheese production. Appl. Environ. Microbiol. 72, 6124-6135. 
Lee, J., Heo, G., Lee, J.W., Oh, Y., Park, J.A., Park, Y., Ryun, Y., Ahn, J.S., 2005. Analysis of kimchi microflora using denaturing gradient gel electrophoresis. Int. J. Food Microbiol. 102, 143-150.

Lin, C.W., Chen, H.L., Liu, J.R., 1999. Identification and characterisation of lactic acid bacteria and yeasts isolated from kefir grains in Taiwan. Aust. J. Dairy Technol. 54, 14-18.

Mainville, I., Robert, N., Lee, B., Farnworth, E.R., 2006. Polyphasic characterization of the lactic acid bacteria in kefir. Syst. Appl. Microbiol. 29, 59-68.

Marshall, V.M., Cole, W.M., 1985. Methods for making kefir and fermented milks based on kefir. J. Dairy Res. 52, 451-456.

Ninane, V., Mukandayambaje, R., Berben, G., 2007. Identification of lactic acid bacteria within the consortium of kefir grain by sequencing 16S rDNA variable regions. J. AOAC Int. 90, 1111-1117.

Prakitchaiwattana, C.J., Fleet, G.H., Heard, G.M., 2004. Application and evaluation of denaturing gradient gel electrophoresis to analyse the yeast ecology of wine grapes. FEMS Yeast Res. 4, 865-877.

Simova, E., Beshkova, D., Angelov, A., Hristozova, T., Frengova, G., Spasov, Z., 2002. Lactic acid bacteria and yeasts in kefir grains and kefir made from them. J. Ind. Microbiol. Biotechnol. 28, 1-6.

St-Onge, M.P., Farnworth, E.R., Savard, T., Chabot, D., Mafu, A., Jones, P.J., 2002. Kefir consumption does not alter plasma lipid levels or cholesterol fractional synthesis rates relative to milk in hyperlipidemic men: a randomized controlled trial. BMC Complement. Altern. Med. 2, 1-7.

Takizawa, S., Kojima, S., Tamura, S., Fujinaga, S., Benno, Y., Nakase, T., 1994. Lactobacillus kefirgranum sp. nov. and Lactobacillus parakefir sp. nov., two new species from kefir grains. Int. J. Syst. Bacteriol. 44, 435-439.

Takizawa, S., Kojima, S., Tamura, S., Fujinaga, S., Benno, Y., Nakase, T., 1998. The composition of the Lactobacillus flora in kefir grains. Syst. Appl. Microbiol. 21, 121-127.
Temmerman, R., Huys, G., Swing, J., 2004. Identification of lactic acid bacteria: culture-dependent and culture-independent methods. Trends Food Sci. Technol. 15, 348-359.

Theunissen, J., Britz, T.J., Torriani, S., Witthuhn, R.C., 2005. Identification of probiotic microorganisms in South African products using PCR-based DGGE analysis. Int. J. Food Microbiol. 98, 11-21.

van Beek, S., Priest, F.G., 2002. Evolution of the lactic acid bacterial community during malt whisky fermentation: a polyphasic study. Appl. Environ. Microbiol. 68, 297-305.

Vujičič, I.F., Vulić, M., Könyves, T., 1992. Assimilation of cholesterol in milk by kefir cultures. Biotechnol. Lett. 14, 847-850.

Walter, J., Tannock, G.W., Tilsala-Timisjarvi, A., Rodtong, S., Loach, D.M., Munro, K., Alatossava, T., 2000. Detection and identification of gastrointestinal Lactobacillus species by using denaturing gradient gel electrophoresis and species-specific PCR primers. Appl. Environ. Microbiol. 66, 2418-2423.

Ward, L.J.H., Brown, J.C.S., Davey, G.P., 1998. Two methods for the genetic differentiation of Lactococcus lactis ssp. lactis and cremoris based on differences in the 16S rRNA gene sequence. FEMS Microbiol. Lett. 166, 15-20.

Witthuhn, R.C., Schoeman, T., Britz, T.J., 2004. Isolation and characterization of the microbial population of different South African kefir grains. Int. J. Dairy Technol. 57, 33-37.

Witthuhn, R.C., Schoeman, T., Britz, T.J., 2005. Characterisation of the microbial population at different stages of kefir production and kefir grain mass cultivation. Int. Dairy J. 15, 383-389.

Zoetendal, E.G., Akkermans, A.D.L., de Vos, W.M., 1998. Temperature gradient gel electrophoresis analysis of 16S rRNA for human fecal samples reveals stable and host-specific communities of active bacteria. Appl. Environ. Microbiol. 64, 3854-3859. 